\title{
An Insight into the Role of Benefical Bacteria in Periodontal Pocket Recolonization: A Literature Review
}

\author{
Suchetha $\mathrm{A}^{1}$, Apoorva SM${ }^{2}$, Mundinamane $\mathrm{DB}^{3}$, Bhopale DP ${ }^{4}$, Bharwani $\mathrm{A}^{5}$, Prasad $\mathrm{R}^{6}$
}

\begin{abstract}
Microflora can be found in both caries-free and periodontitis-free people and caries-affected and periodontitisaffected people, and many clinical studies reveal that the portion of certain bacterial species such as Streptococcus mutans or Porphyromonas gingivalis, respectively, is increased in patients with caries or periodontitis. Therefore, it seems that the competition that results between beneficial bacteria and virulent bacteria leads to either a healthy or sick status of human beings. Competition between members of the dental microflora and there role in pocket recolonization is very complex and many antagonistic characteristics can be observed from competition for initial attachment on tooth surfaces or for later attachment to pioneer bacteria, competition from bacteriocins or hydrogen peroxide secreted and from facilitating the growth of some species which inhibit other species. To date only some of the details of these mechanisms are known. The present review will provide an overview on the prevalence of beneficial bacteria and the major mechanisms of oral bacterial interactions. Due to the large number of oral bacterial species, only the best characterized species are included in this review.
\end{abstract}

Keywords: Microflora, Beneficial bacteria, Pocket recolonization, Bacteriocins

${ }^{1}$ Professor and Head

Department of Periodontics

DAPMRV Dental College, Bangalore, Karnataka

${ }^{2}$ Senior lecturer

Department of Periodontics

DAPMRV Dental College, Bangalore, Karnataka

${ }^{3}$ Reader

Department of Periodontics

DAPMRV Dental College, Bangalore, Karnataka

${ }^{4}$ Post Graduate Student

Department of Periodontics

DAPMRV Dental College, Bangalore, Karnataka

${ }^{5}$ Private Practitioner (Ex-Post Graduate Student) Department of Periodontics

DAPMRV Dental College, Bangalore, Karnataka

${ }^{6}$ Private Practitioner (Ex-Post Graduate Student) Department of Periodontics

DAPMRV Dental College, Bangalore, Karnataka

\section{Contact Autbor}

Dr. Dinesh P Bhopale

perio_rvdc@yahoo.com

J Oral Health Comm Dent 2014;8(1)47-50
$\mathrm{P}^{\mathrm{N} T \mathrm{n}}$

Priodontal diseas

1 inflammation, periodontal pocket formation, and loss of connective tissue attachment and alveolar bone around the affected teeth (1). The current concept concerning the etiology of periodontitis considers 3 groups of factors that determine whether active periodontitis will occur in a subject: a susceptible host, the presence of pathogenic species and the absence of so called "beneficial bacteria" (2). Beneficial species of the indigenous oral microbiota and their role in epithelial colonization of oral pathogens are largely unexplored.

Therapeutic treatments have always aimed at removal of periodontopathogens from the subgingival area and worldwide-accepted strategies consist of scaling and root planning which is considered as a gold standard treatment modality(3). However, recolonization toward pre-treatment levels, primarily by bacteria less strongly implicated as periodontopathogens, occurs within weeks (4), and re-establishment of a more pathogenic microbiota occurs within months (5). Adjunctive use of local or systemic antibiotics and antiseptics improves the outcome of periodontal therapy only temporarily (3). Thus, a life-long need for (re) treatment arises, creating a serious socio-economic problem.

In the past few years, probiotics have been investigated for periodontal health (6). Studies have shown that certain gut bacteria can exert beneficial effects in the oral cavity by inhibiting pathogenic species. The concept of periodontal replacement therapy, first proven by Teughels et al, consists of applying beneficial oral bacteria subgingivally to prevent re-colonization of periodontal pockets by pathogens 
after scaling and root planning (7). Given the emergence of antibiotic resistance and the lack of nonantibiotic treatment options, this Guided Pocket Recolonization approach may provide a valuable addition or alternative to the armamentarium of treatment options for periodontitis.

\section{PREVALENCE OF BENEFICIAL BACTERIA IN PERIODONTAL HEALTH AND GINGIVITIS}

Beneficial bacteria have been extensively studied for their health-promoting effects. Studies have established the succession of bacterial morphotypes with progression from periodontally healthy sites (predominated by gram-positive cells) to gingivitis (predominated by gram-negative cells) (8). Kilian showed that $63-86 \%$ of the initial colonizing bacteria were streptococci along with some actinomyces and veillonellae (9). In accordance with various studies the initial communities from all subjects were dominated by Streptococcus spp. belonging to the S. oralis/Streptococcus mitis group. The most abundant phylotypes, apart from those classified as streptococci, belonged to the genera Actinomyces, Gemella, Granulicatella, Neisseria, Prevotella, Rothia and Veillonella, as well as uncultured species from the class Clostridia (10). The initial communities of some subjects contained gram-negative anaerobic bacteria such as Prevotella allows the formation of microenvironments in which cell-cell interactions easily occur. Study by listgarten et al revealed that the health-associated microbiota consisted of a thin layer of adherent bacterial cells with the characteristics of gram-positive cocci. In contrast, the samples from teeth with gingivitis contained a greater variety of morphotypes, including coccoid and filamentous forms, as well as gram-positive and gram-negative bacteria. Numerous examples of distinct morphotypes in close association (coaggregation) are seen at the periphery of developing plaque (11).
However studies showed that, in samples from oral sites where S. sanguinis was detected, Tannerella forsythia was present in $1 \%$ of the cases, and in samples were S. sanguinis was not detected; Tannerella forsythia was present in $10 \%$ of the oral sites (12).

\section{PREVALENCE OF BENEFICIAL BACTERIA IN CHRONIC PERI- ODONTITIS}

In a clinical study samples from teeth with chronic periodontitis patients, contained a dense, predominantly filamentous, supragingival plaque and a subgingival component containing flagellated bacteria, spirochetes and small gram-negative bacteria (11), this study demonstrated that the maturation of plaque is accompanied by changes in the predominant bacterial species, close association of distinct bacterial morphotypes and an increase in bacterial diversity over time.

In another clinical study supra- and subgingival plaque were examined in clinically healthy subjects and in periodontitis patients for the same 40 bacterial taxa in a DNA checkerboard analysis and found similar species in both supra- and subgingival plaque samples from healthy and diseased sites. However, they observed a higher mean prevalence of the Actinomyces species in health, with the diseased (deeper) sites tending to have higher counts of bacteria overall as well as greater proportions of the more pathogenic 'orange' and 'red' complexes of bacteria including Tannerella forsythia, Porphyromonas gingivalis, Treponema denticola, and Prevotella intermedia (13).

In contrast, studies have also shown that $S$. sanguinis and $S$. oralis did not differ among the subject group of periodontitis patients, healthy controls and elders with a well-maintained periodontitis (14), other studies have reported that $\mathrm{S}$. sanguinis was more prevalent in shallow sites but was not the species associated with health (15).

\section{PREVALENCE OF BENEFICIAL BACTERIA IN AGGRESSIVE PERIODONTITIS}

The prevalence of oral streptococcal species in the subgingival biofilm of patients with aggressive periodontitis and healthy controls was investigated. S. oralis was the most prevalent oral streptococcus in both groups of subjects (present in $70 \%$ of cases), but $\mathrm{S}$. sanguinis was the second most common isolate (present in $90 \%$ of healthy subjects and $45 \%$ of periodontitis patients). S. mitis was present in both groups in $36-40 \%$ of cases. Aggressive periodontitis seems to be associated with a loss of colonization with $\mathrm{S}$. sanguinis, Whether or not $S$. sanguinis offers protection against aggressive periodontitis needs to be determined (16). Studies have demonstrated that $\mathrm{S}$. gordonii plays a role in colonization with Porphyromonas gingivalis further studies are needed to clarify the possible relationship between S. gordonii and periodontal status (17).

\section{ROLE OF BENEFICIAL BACTE- RIA IN PERIODONTIUM}

As such bacteria can affect disease progression in different ways: (i) by "passively" occupying a niche which might otherwise be colonized by pathogens, (ii) by actively limiting a pathogen's ability to adhere to the appropriate tissue surfaces, (iii) by adversely affecting the vitality or growth of a pathogen, (iv) by affecting the ability of a pathogen to produce virulence factors, and/ or (v) by degrading virulence factors produced by the pathogen $(2,18)$.

S. sanguinis is one of the early colonizers in biofilm. It can produce hydrogen peroxide as a means of excreting excessive oxygen, which serves as a non-specific antimicrobial agent, which can inhibit S. mutans and anaerobic periodontal pathogens growth. Studies showed that one-third of $\mathrm{S}$. sanguinis strains tested were able to inhibit Prevotella intermedia. In vitro growth of Aggregatibacter actinomycetemcomitans was inhibited by the hydro- 
gen peroxide produced by $S$. sanguinis (12). However, A. actinomycetemcomitans may produce a bacteriocin that can kill S.sanguinis (19), so there is an inverse relationship between these bacteria. In a complex ecosystem such as dental biofilm, these relationships may contribute to the transition from health to disease. Also, in-vitro studies have shown that $\mathrm{S}$. sanguinis (as well as $\mathrm{S}$. mitis and Streptococcus salivarius) has protective properties that interfere with A. actinomycetemcomitans colonization of epithelial cells (7). All of these data suggest that $S$. sanguinis may serve as a 'protective' bacterium as defined by Quirynen et al (20). The effect of $S$. sanguinis on the presence of Porphyromonas gingivalis is still under debate. Whilst studies, showed that $\mathrm{S}$. sanguinis had a minimal effect on the presence of Porphyromonas gingivalis, another study showed that pre-colonization and superinfection with S. sanguinis reduced the level of Porphyromonas gingivalis in experimental rats (21).

In an in-vitro study the capacity of six antagonistic bacteria(Streptococcus sanguinis, Streptococcus crista, Streptococcus salivarius, Streptococcus mitis, Actinomyces naeslundii, and Haemophilus parainfluenzae) to block the attachment of periodontopathogens (P. gingivalis, $P$. intermedia and $\mathrm{A}$. actinomycetemcomitans), the results showed that $A$. naeslundii, H. parainfluenzae, and S. mitis cause the strongest blocking of $\mathrm{P}$. gingivalis adhesion but have considerably less effect on the adhesion of $P$. intermedia and A. actinomycetemcomitans, suggesting that the blocking effect is caused by interactions, specific to each combination of an antagonist and periodontopathogen. Indeed, blocking is determined by repulsive interactions between the adhering antagonist and the periodontopathogen and larger blocking effects may arise, for instance, from biosurfactant production (22). Reports have also shown, instead of antagonistic effects, synergistic effects of
A. naeslundii on $\mathrm{P}$. gingivalis through co-aggregation (23) and enhancement of $\mathrm{P}$. gingivalis adhesion (24). However, because it is clinically known that Actinomyces occurs more in healthy pockets than in diseased pockets (25), we believe that the A. naeslundii strain studied here may be considered as an antagonist of $P$. gingivalis. Streptococcus crista might also be considered as antagonistic because it down regulates FimA expression (26), while Streptococcus salivarius inhibits the emergence of mutans streptococci (25).

Lactobacillus. paracasei produces bacteriocins, which make pores in the cytoplasmic membranes of $\mathrm{P}$. gingivalis, P. intermedia, T. forsythia, S. salivarius and $S$. sanguinis, inhibiting the growth of those strains (19).

\section{EFFECT OF REPLACEMENT THERAPY ON PERIODONTIUM}

Animal study performed to test the concept of bacterial replacement therapy in the treatment of plaquerelated periodontal disease, this study assessed quantitative changes in the subgingival microbiota after root planing when beneficial bacteria were applied adjunctively. Although application of beneficial bacteria did not exclude pathogen recolonization, it did delay the recolonization process significantly. Inoculation of beneficial bacteria immediately after root planing, and especially with additional inoculation during the recolonization process, significantly lowered bacterial counts for all monitored pathogens (7).

In another animal study evaluated radiologically the impact of replacement therapy by monitoring bone density changes and alveolar bone level in periodontal pockets in a dog model. The bone density within periodontal pockets treated with beneficial bacteria improved significantly after 12 weeks, there was a significant increase in the bone level at the end of the study for the pockets receiving beneficial bacteria, and no significant changes were noted in the control pockets (27).

\section{CONCLUSION}

The literature as it currently stands appears to indicate that oral dysbiosis, or a shift from beneficial symbiotic bacteria to pathogenic bacteria, is at least partially responsible for the development of periodontitis. However, despite great advances in our knowledge of the underlying microbial basis of this disease, the fact still remains that periodontitis has multiple etiologies which have yet to be fully understood. Thus, while a microbial shift is known to play a significant role in the development of periodontitis, genetic, immunologic, and environmental factors have also got a role. Because of the various risk factors that contribute to periodontitis, it is possible that there will be no "magic bullet" treatment. Recent advances show tremendous potential to help patients suffering from periodontitis. Host modulation therapy, photodynamic therapy, and replacement therapy may provide advantages not observed when antibiotics or antiseptics are used. However, much research still needs to be conducted on these new alternatives. Most importantly, well-designed and large-scale randomized clinical trials need to be performed comparing the "gold standard" of scaling and root planing to the new therapies used alone or adjunctively with scaling and root planing. Additionally, the future development of the " $\$ 1000$ genome" may help clinicians identify mutations in their patients' DNA which might predispose them to aberrant immune responses (28). Overall, the goal for both researchers and clinicians is to find the best treatment. From a biological perspective, the most successful treatments will likely need to attack the integrity of the periodontal biofilm and suppress the destructive host inflammatory response. From a clinical perspective, the best treatments are those that are simple, affordable, and able to confer a clinically relevant benefit to the patient. 


\section{REFERENCES}

1. Listgarten MA. Pathogenesis of Periodontitis. J Clin Periodontol 1986;13(5):418-30.

2. Haffajee AD, Socransky SS. Microbial etiological agents of destructive periodontal diseases. Periodontol 2000 1994;5:78-111.

3. Quirynen M, Teughels W, De Soete M, van Steenberghe D. Topical antiseptics and antibiotics in the initial therapy of chronic adult periodontitis: microbiological aspects. Periodontol 2000 2002;28:72-90.

4. Harper DS, Robinson PJ. Correlation of histometric, microbial and clinical indicators of periodontal disease status before and after root planing. J Clin Periodontol 1987;14(4):190-96.

5. Magnusson I, Lindhe J, Yoneyama $\mathrm{T}$, Liljenberg B. Recolonization of a subgingival microbiota following scaling in deep pockets. J Clin Periodontol 1984;11(3):193-207.

6. Teughels W, Van Essche M, Sliepen I, Quirynen M. Probiotics and oral health. Periodontol 2000 2008;48:111-47.

7. Teughels W, Newman MG, Coucke W, Haffajee AD, Van Der Mei HC, Haake $\mathrm{SK}$, et al. Guiding periodontal pocket recolonization: a proof of concept. J Dent Res 2007;86(11):1078-82.

8. Loe H, Theilade E, Jensen SB. Experimental gingivitis in man. $J$ Periodontol 1965;36:177-87.

9. Nyvad B, Kilian M. Comparison of the initial streptococcal microflora on dental enamel in caries-active and in caries in active individuals. Caries Res 1990;24(4):267-72.

10. Kolenbrander PE, Palmer RJ Jr, Rickard AH, Jakubovics NS, Chalmers NI, Diaz $\mathrm{PI}$. Bacterial interactions and successions during plaque development. Periodontol 2000 2006;42:47-79.

11. Listgarten MA. Structure of the microbial flora associated with periodontal health and disease in man A light and electron microscopic study. J Periodontol 1976;47(1):1-18.

12. Hillman JD, Socransky SS, Shivers M. The relationships between streptococcal species and periodontopathic bacteria in human dental plaque. Arch Oral Biol 1985;30(11-12):791-95.

13. Ximénez-Fyvie LA, Haffajee AD, Socransky SS. Comparison of the microbiota of supra- and subgingival plaque in health and periodontitis. $J$ Clin Periodontol 2000;27(9):648-57.

14. Haffajee AD, Cugini MA, Tanner A, Pollack RP, Smith C, Kent RL Jr, Socransky SS. Subgingival microbiota in healthy, well-maintained elder and periodontitis subjects. J Clin Periodontol 1998;25(5):346-53.

15. Dowsett SA, Kowolik MJ, Archila LA, Eckert GJ, LeBlanc DJ. Subgingival microbiota of indigenous Indians of Central America. J Clin Periodontol 2002;29(2):159-67.

16. Stingu CS, Eschrich K, Rodloff AC, Schaumann $\mathrm{R}$, Jentsch $\mathrm{H}$. Periodontitis is associated with a loss of colonization by Streptococcus sanguinis. J Med Microbiol 2008;57(Pt 4):495-99.

17. Daep CA, James DM, Lamont RJ, Demuth DR. Structural characterization of peptidemediated inhibition of Porphyromonas gingivalis biofilm formation. Infect Immun 2006;74(10):5756-62.

18. Grenier D. Antagonistic effect of oral bacteria towards Treponema denticola. J Clin Microbiol 1996;34(5):1249-52.

19. Huang R, Li M, Gregory RL. Bacterial interactions in dental biofilm. Virulence 2011;2(5):435-44.

20. Quirynen M, De Soete M, Dierickx $K$, van Steenberghe $D$. The intraoral translocation of periodontal pathogens jeopardises the outcome of periodontal therapy. J Clin Periodontol 2001;28(6):499-507.

21. Zhang JC, Zhou C, Wu B, Zhang $\mathrm{YH}$. Investigation on interaction between Streptococcus sanguis and Porphyromonas gingivalis in specific pathogen-free rats. Chin $J$ Dent Res 2000;3(4):5-9.

22. Van Hoogmoed CG, GeertsemaDoornbusch GI, Teughels W, Quirynen M, Busscher HJ, Van der Mei HC. Reduction of periodontal pathogens adhesion by antagonistic strains. Oral Microbiol Immunol 2008;23(1):43-48

23. Yamaguchi $T$, Kasamo $K$, Chuman $M$, Machigashira M, Inoue M, Sueda T. Preparation and characterization of an Actinomyces naeslundii aggregation factor that mediates coaggregation with Porphyromonas gingivalis. J Periodontal Res 1998;33(8):460-68.

24. Sato $M$, Nagayama M, Yamaguchi $R$, Fujiwara S, Takeuchi H. Influence of secondary colonizers and human plasma on the adherence of Porphyromonas gingivalis in vitro. Eur $J$ Oral Sci 2002;110(3):225-29.

25. Moore LV, Moore WE, Cato EP, Smibert RM, Burmeister JA, BestAM, Ranney RR. Bacteriology of human gingivitis. J Dent Res 1987;66(5):989-95.

26. Xie H, Cook GS, Costerton JW, Bruce G, Rose TM, Lamont RJ. Intergeneric communication in dental plaque biofilms. J Bacteriol 2000;182(24):7067-69.

27. Nackaerts O, Jacobs R, Quirynen M, Rober M, Sun Y, Teughels W. Replacement therapy for periodontitis: pilot radiographic evaluation in a dog model. J Clin Periodontol 2008;35(12):1048-52.

28. Shendure J, Mitra RD, Varma C, Church GM. Advanced sequencing technologies: methods and goals. Nat Rev Genet 2004;5(5):335-44. 